\title{
Загрязнение горного озера стоками апатит-нефелинового производства
}

\author{
Даувальтер М.В. ${ }^{1}$, Даувальтер В.А. ${ }^{2}$ Денисов Д.Б. ${ }^{2}$, Слуковский 3.И. ${ }^{2,3}$ \\ ${ }^{1}$ Геологический институт КНЦ РАН, Anamumbl, dauvalter@geoksc.apatity.ru \\ ${ }^{2}$ Институт проблем промышленной экологии Севера КНЦ РАН, Anamumbl,v.dauvalter@ksc.ru \\ ${ }^{3}$ Институт геологии КарНЦ РАН, Петрозаводск, slukovsky87@gmail.com
}

Аннотация. Приведены результаты 10-летних мониторинговых гидрохимических исследований и проведена оценка качества озера Комариное, расположенного на территории разработки апатит-нефелинового месторождения Олений ручей. Выявлено увеличение величины рН воды, минерализации, содержания и соотношения главных ионов, соединений азотной группы $\left(\mathrm{NO}_{2}^{-}\right.$и $\left.\mathrm{NO}_{3}^{-}\right)$в последние годы, а также ряда микроэлементов ( $\mathrm{Sr}, \mathrm{Mo}, \mathrm{Cu}, \mathrm{F})$, в несколько раз превышающие величину предельно допустимых концентраций вредных веществ для воды рыбохозяйственных водоемов. По содержанию биогенных элементов озеро в настоящее время характеризуется как эвтрофное. Резкое увеличение содержания соединений биогенного элемента (азота) может привести к развитию цветения потенциально токсичных цианобактерий. Озеро Умбозеро, которое получает воду из озера Комариное, также подвержено риску развития процессов цветения воды и загрязнения.

Ключевые слова: апатит-нефелиновые месторождения, Хибины, качество вод, поверхностные воды.

\section{Contamination of a mountain lake by wastewaters of apatite-nepheline production}

\author{
Dauvalter M.V. ${ }^{1}$, Dauvalter V.A. ${ }^{2}$, Denisov D.B. ${ }^{2}$, Slukovskii Z.I. ${ }^{2,3}$ \\ ${ }^{1}$ Geological Institute Kola SC RAS, Apatity,dauvalter@geoksc.apatity.ru \\ ${ }^{2}$ Institute of North Industrial Ecology Problems Kola SC RAS, Apatity,v.dauvalter@ksc.ru \\ ${ }^{3}$ Institute of Geology of Karelian Research Centre of RAS, Petrozavodsk, slukovsky87@gmail.com
}

Abstract. The results of 10-year monitoring studies of the chemical composition of water are given and the quality of Lake Komarinoe, located on the territory of the development of the Oleniy Ruchey apatite-nepheline deposit, is assessed. An increase in the $\mathrm{pH}$ value of water, mineralization, content and ratio of the main ions, nutrients $\left(\mathrm{NO}_{2}^{-}\right.$and $\left.\mathrm{NO}_{3}^{-}\right)$in recent years, as well as trace elements ( $\left.\mathrm{Sr}, \mathrm{Mo}, \mathrm{Cu}, \mathrm{F}\right)$, several times exceeding the value of the maximum permissible concentrations of harmful substances for the water of fishery reservoirs. According to the content of nutrients, the lake is currently characterized as eutrophic. A sharp increase in the content of nutrients can lead to the development of a bloom of potentially toxic cyanobacteria. Lake Umbozero, which receives water from Lake Komarinoe, is also at risk of water bloom and pollution.

Key words: apatite-nepheline deposits, Khibiny, water quality, surface water.

\section{Введение}

Одним из наиболее мощных факторов антропогенного преобразования окружающей среды, в том числе природных вод, являются горнодобывающая промышленность. В работах (Мироненко и др., 1988, 1989; Даувальтер, Кашулин, 2015) описаны последствия влияния техногенного воздействия горнодобывающих предприятий на подземные и поверхностные воды. Изменения химического состава поверхностных вод обусловлены поступлением загрязняющих веществ из поверхностных техногенных накоплений (пруды-отстойники, массивы отвальных пород и т.п.) и нарушением естественного гидродинамического и гидрохимического режима поверхностных и подземных вод (Даувальтер, Даувальтер, 2019, 2020).

Акционерное общество «Северо-Западная Фосфорная Компания» (АО «СЗФК») учреждено ПАО «Акрон» в 2005 г. для реализации проекта по созданию новой фосфорной сырьевой базы в Мурманской области. В ноябре 2006 г. АО «СЗФК» получило лицензию на право пользования недрами месторождений апатит-нефелиновых руд Олений Ручей и Партомчорр. В 2012 г. завершено строительство первой очереди ГОК, выполнены пусконаладочные работы в корпусах обогатитель- 
ной фабрики, получены первые тонны апатитового концентрата. С июня 2013 г. АО «СЗФК» полностью обеспечивает потребности российских химических предприятий группы «Акрон» в фосфатном сырье. Как утверждает руководство АО «СЗФК», основным принципом экологической политики компании является устойчивое развитие при максимально рациональном использовании природных ресурсов и сохранении благоприятной окружающей среды для будущих поколений. Компания проводит масштабную работу по исследованию негативных факторов действующего производства и их подавлению. Возможное воздействие на природоохранные объекты от эксплуатации промышленного предприятия сводится к минимуму (https://www.szfk.ru/). Целью данной работы является оценка загрязнения и динамика качества поверхностных вод Хибинского щелочного массива в результате разработки апатит-нефелиновых месторождений на примере оз. Комариное.

\section{Материалы и методы}

Озеро Комариное (водосбор р. Умба) расположено на юго-востоке Хибинского щелочного массива, в 8.9 км на северо-восток от пос. Коашва (Кашулин и др., 2012). Это небольшое (площадь 0.66 км$\left.^{2}\right)$, по форме близкое к овальной, озеро ледникового происхождения, наибольшая длина которого - 1.53 км, наибольшая ширина - 0.65 км, высота над уровнем моря 174 м (рис.). Территория водосборной площади по типу ландшафтов относится к лесотундровой зоне с высотами до 600 м. Берега озера высокие, каменистые. На водосборной площади озера до начала разработки месторождения были распространены березовые и сосновые леса.

Химический состав воды оз. Комариное исследовался в течение последних 10 лет с 2011 по 2020 гг. Пробы озерных вод отбирались сотрудниками АО «СЗФК» 4 раза в год - в конце зимы (март-апрель), в половодье (июнь), в летнюю межень (август), в начале зимнего периода (октябрьноябрь). Анализ проб воды проводился в аккредитованной лаборатории ОАО КГИЛЦ: определялись значения $\mathrm{pH}$, жесткость, ионный состав $\left(\mathrm{Na}^{+}, \mathrm{K}^{+}, \mathrm{Ca}^{2+}, \mathrm{Mg}^{2+}, \mathrm{NH}_{4}^{+}, \mathrm{HCO}_{3}^{-}, \mathrm{SO}_{4}^{2-}, \mathrm{Cl}^{-}, \mathrm{NO}_{3}^{-}, \mathrm{F}^{-}\right)$, содержание микроэлементов ( $\mathrm{Al}, \mathrm{Fe}, \mathrm{Mn}, \mathrm{Sr}, \mathrm{Cu}, \mathrm{Zn}, \mathrm{Ni}, \mathrm{Co}, \mathrm{Cr}, \mathrm{Cd}, \mathrm{Pb}, \mathrm{Mo}, \mathrm{Hg}, \mathrm{B}, \mathrm{Be}, \mathrm{Ba}$ ). В данной работе проведен анализ динамики химического состава воды оз. Комариное до начала и за период разработки месторождения.

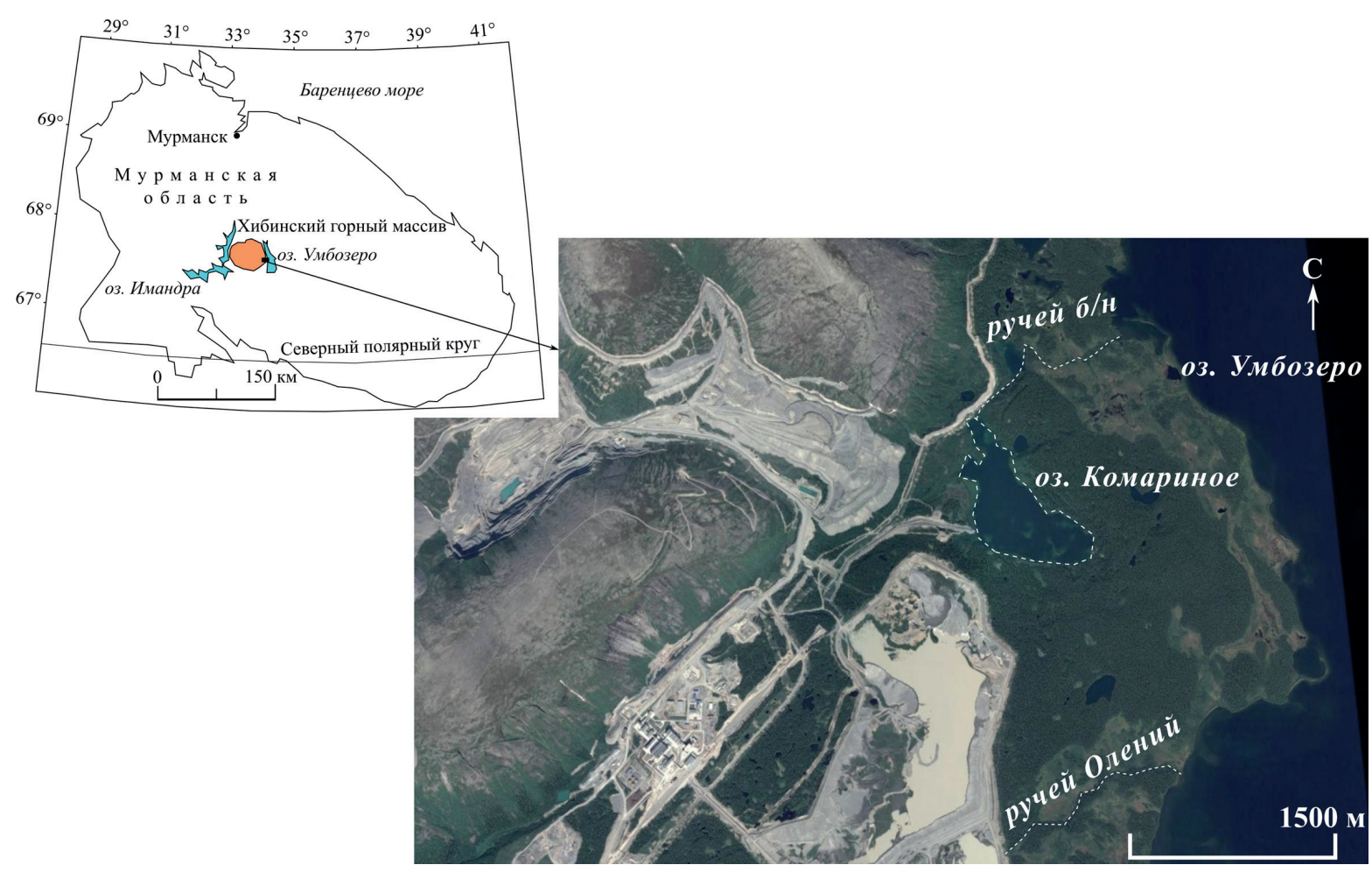

Рис. Карта-схема расположения оз. Комариное.

Fig. Schematic map of the location of Lake Komarinoe. 


\section{Результаты и обсуждение}

Вода в оз. Комариное до начала деятельности АО «СЗФК» была нейтральной, гидрокарбонатнонатриевого состава и характеризовалась невысокими значениями общей минерализации (в среднем 35 мг/л) (Кашулин и др., 2012). Изменение химического состава воды легче всего проследить по соотношению главных ионов, входящих в состав воды. Формула ионного состава воды (Курлова) оз. Комариное в это время выглядела следующим образом:

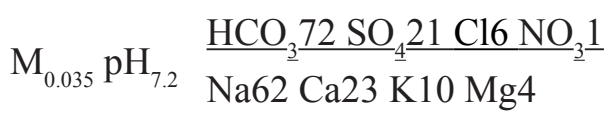

В самом начале деятельности АО «СЗФК» в 2011 г. формула Курлова воды оз. Комариное оставалась практически в неизменном виде:

$$
\mathrm{M}_{0.040} \mathrm{pH}_{7.3} \frac{\underline{\mathrm{HCO}}_{3}}{\mathrm{Na}_{2} \mathrm{Ca} 20 \mathrm{KO} 12 \mathrm{Mg} 8} \frac{18 \mathrm{Cl} 15 \mathrm{NO}_{2}}{2} \underline{2}
$$

Спустя десятилетие, весной 2020 г. эта формула претерпела значительные изменения, особенно в соотношении главных анионов:

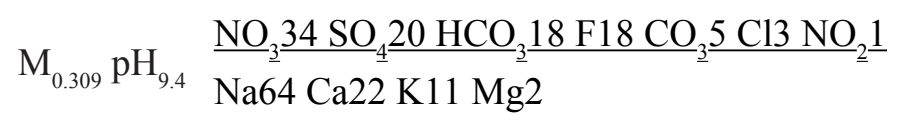

Добыча и переработка апатит-нефелиновых руд, выветривание вскрышных щелочных пород привело к увеличению содержания главных ионов и минерализации, что было отмечено за 10-летний период гидрохимического мониторинга оз. Комариное (табл.).

Гидрокарбонат-ион являлся преобладающим анионом в воде оз. Комариное в природном состоянии, на втором месте был сульфат-ион, на третьем - хлорид-ион, т.е. для этого озера было характерно «классическое» распределение в поверхностных водах как Хибинского щелочного массива, так и Мурманской области в целом (Кашулин и др., 2008; Даувальтер, Даувальтер, 2014). Весной 2020 г. было зафиксировано, что на первое место среди анионов переместился нитрат-ион, на второе - сульфат-ион, а обычно превалирующий гидрокарбонат-ион занимает третье место, т.е. вода озера имеет явно техногенное происхождение. При добыче апатит-нефелиновых руд на АО «СЗФК» используют азотсодержащие взрывчатые вещества, которые значительно увеличивают содержание в поверхностных водах азотных соединений. Содержание нитрат-иона $\mathrm{NO}_{3}{ }^{-}$в последние годы растет в степенной прогрессии, и за последние 10 лет увеличилось почти на 2 порядка, превышая величину предельно допустимой концентрации для воды рыбохозяйственных водоемов ПДК (табл.). В последние годы более чем на порядок увеличилось и содержание другого более опасного иона азотной группы - нитрит-ион $\mathrm{NO}_{2}^{-}$, намного превышающего значение ПДК

Особенностью химического состава воды оз. Комариное, как и всех природных вод Хибинского щелочного массива (Даувальтер, Даувальтер, 2019, 2020; Dauvalter et al., 2020), является преимущественное преобладание катиона $\mathrm{Na}^{+}$, а также повышенное относительное содержание катиона $\mathrm{K}^{+}$, которое сопоставимо по концентрациям с катионом $\mathrm{Ca}^{2+}$, тогда как природные воды равнинных территорий Мурманской области, не получающие прямое загрязнение промышленных предприятий, характеризуются гидрокарбонатным классом и кальциевой группой, и катион $\mathrm{K}^{+}$, как правило, находится на последнем месте среди основных катионов (Даувальтер, Даувальтер, 2010, 2014).

За 10-летний период наблюдений происходит достоверное увеличение величины $\mathrm{pH}$ воды оз. Комариное (табл.), что связано с контактированием вод со щелочными породами, содержащими щелочные и щелочноземельные металлы, усилением влияния разработки месторождения и увеличением глубины подземных горных выработок. В соответствии с требованиями к составу и свойствам воды водоемов рыбохозяйственного назначения, величина $\mathrm{pH}$ не должна выходить за пределы значений 6-9. В последнее время максимальные значения величины рН воды оз. Комариное превысило критическое значение 9 (табл.), которое по классификации величины $\mathrm{pH}$ соответствует щелочным водам. Увеличение содержание щелочноземельных металлов привело к повышению жесткости воды оз. Комариное. 
Таблица. Изменение гидрохимических показателей оз. Комариное за последние 10 лет.

Table. Changes in the hydrochemical parameters of Lake Komarinoe over the past 10 years.

\begin{tabular}{|c|c|c|c|c|c|}
\hline \multirow{2}{*}{ Показатели, мг/л } & \multirow{2}{*}{ ПДК } & \multicolumn{4}{|c|}{ Год } \\
\hline & & 2011 & 2014 & 2017 & 2020 \\
\hline \multirow{2}{*}{$\mathrm{Ca}^{2+}$} & \multirow{2}{*}{180} & $\underline{0.80-2.80}$ & $\underline{3.40-5.00}$ & $\underline{12.6-16.8}$ & $\underline{13.4-17.4}$ \\
\hline & & 2.00 & 4.35 & 15.3 & 15.5 \\
\hline \multirow{2}{*}{$\mathrm{Mg}^{2+}$} & \multirow{2}{*}{40} & $\underline{0.12-1.09}$ & $\underline{0.12-0.73}$ & $\underline{0.85-2.42}$ & $\underline{0.60-1.94}$ \\
\hline & & 0.48 & 0.52 & 1.55 & 1.09 \\
\hline \multirow{2}{*}{$\mathrm{Na}^{+}$} & \multirow{2}{*}{120} & $\underline{6.41-7.86}$ & $7.08-10.5$ & $\underline{15.6-24.3}$ & $\underline{24.6-59.3}$ \\
\hline & & 7.13 & 9.03 & 21.5 & 33.6 \\
\hline \multirow{2}{*}{$\mathrm{K}^{+}$} & \multirow{2}{*}{10} & $\underline{1.99-2.49}$ & $2.22-4.18$ & $\underline{5.23-6.35}$ & $\underline{10.4-17.4}$ \\
\hline & & 2.23 & 3.07 & 5.77 & 12.8 \\
\hline \multirow{2}{*}{$\mathrm{HCO}_{3}^{-}$} & \multirow{2}{*}{-} & $20.1-26.3$ & $28.1-31.1$ & $\underline{48.2-68.3}$ & $44.5-60.4$ \\
\hline & & 23.3 & 29.6 & 58.7 & 53.7 \\
\hline \multirow{2}{*}{$\mathrm{SO}_{4}^{2-}$} & \multirow{2}{*}{100} & $\underline{3.29-6.17}$ & $\underline{3.51-5.53}$ & $\underline{11.0-37.1}$ & $\underline{26.6-39.5}$ \\
\hline & & 4.73 & 4.45 & 29.2 & 31.07 \\
\hline \multirow{2}{*}{$\mathrm{F}^{-}$} & \multirow{2}{*}{0.75} & $\underline{0.26-0.46}$ & $\underline{0.35-0.47}$ & $\underline{0.10-0.29}$ & $\underline{0.65-13.7}$ \\
\hline & & 0.35 & 0.39 & 0.21 & 4.00 \\
\hline \multirow{2}{*}{$\mathrm{Cl}^{-}$} & \multirow{2}{*}{300} & $\underline{0.20-0.35}$ & $\underline{0.98-2.01}$ & $3.22-3.68$ & $2.83-4.92$ \\
\hline & & 0.24 & 1.41 & 3.50 & 3.68 \\
\hline \multirow{2}{*}{$\mathrm{NO}_{2}^{-}$} & \multirow{2}{*}{0.08} & $\underline{0.02-0.07}$ & $\underline{0.02-0.06}$ & $\underline{0.06-0.07}$ & $\underline{0.29-1.22}$ \\
\hline & & 0.04 & 0.04 & 0.07 & 0.69 \\
\hline \multirow{2}{*}{$\mathrm{NO}_{3}^{-}$} & \multirow{2}{*}{40} & $\underline{0.4-1.12}$ & $2.87-9.79$ & $\underline{14.9-23.4}$ & 35.6-84.3 \\
\hline & & 0.74 & 5.66 & 18.2 & 48.37 \\
\hline \multirow{2}{*}{ Минерализация } & \multirow{2}{*}{-} & $\underline{34-46}$ & $\underline{54-73}$ & $\underline{120-162}$ & $\underline{158-309}$ \\
\hline & & 41 & 62 & 145 & 203 \\
\hline \multirow{2}{*}{$\mathrm{pH}$} & \multirow{2}{*}{$6-9$} & $7.15-7.49$ & 7.09-7.67 & $7.59-8.11$ & $6.62-9.41$ \\
\hline & & 7.30 & 7.34 & 7.79 & 7.89 \\
\hline \multirow{2}{*}{ Mo } & \multirow{2}{*}{0.001} & $\underline{0.001-0.005}$ & $\underline{0.001-0.003}$ & $\underline{0.001-0.008}$ & $\underline{0.003-0.011}$ \\
\hline & & 0.002 & 0.002 & 0.006 & 0.009 \\
\hline \multirow{2}{*}{$\mathrm{Sr}$} & 0.4 & $\underline{0.032-0.087}$ & $\underline{0.097-0.160}$ & $\underline{0.20-0.48}$ & $\underline{0.41-0.61}$ \\
\hline & 0.4 & 0.063 & 0.129 & 0.40 & 0.50 \\
\hline $\mathrm{Cu}$ & 0.001 & $\underline{0.001-0.003}$ & $\underline{0.001-0.005}$ & $\underline{0.001-0.007}$ & $\underline{0.001-0.045}$ \\
\hline $\mathrm{cu}$ & 0.001 & 0.002 & 0.003 & 0.00 & 0.013 \\
\hline
\end{tabular}

В составе горных пород Хибинского щелочного массива (в пегматитах и мельтейгит-уртитах) широко распространены минералы, содержащие $\mathrm{Mo}$ - молибденит $\mathrm{MoS}_{2}$ молибдит $\mathrm{MoO}_{3}$, вульфенит $\mathrm{PbMoO}_{4}$ и ферримолибдит $\mathrm{Fe}_{2}\left(\mathrm{MoO}_{4}\right)_{2} \cdot 8 \mathrm{H}_{2} \mathrm{O}$ (Сулименко и др., 2017). Условия нахождения молибденита детально охарактеризованы А.Н. Лабунцовым, которым в 1927 г. было открыто молибденитовое месторождение Тахтарвумчорр (Красоткин и др., 2005). В природных водах, приуроченных к районам разработки хибинских апатит-нефелиновых месторождений, обнаружено присутствие Мо в количествах, значительно превышающих ПДК др., 2017; Чукаева, Матвеева, 2018). В воде оз. Комариное содержание Мо увеличивается в последние годы и превышает ПДК

Главным рудным минералом месторождения Олений ручей является фторапатит $\left(\mathrm{Ca}_{5}\left(\mathrm{PO}_{4}\right)_{3} \mathrm{~F}\right)$, который при выветривании поставляет F в природные воды в повышенных концентрациях. В природных водах территорий, подверженных влиянию разработки апатит-нефелиновых месторождений, отмечены повышенные содержания F (Кашулин и др., 2008). В воде оз. Комариное содержание F вплотную превышает величину ПДК 
Для нефелиновых сиенитов Хибинского горного массива $\mathrm{Sr}$ является типоморфным элементом (Добровольский, 1972). За время проведения мониторинга установлено достоверное увеличение содержания $\mathrm{Sr}$ воде оз. Комариное и в последние годы оно превышает величину ПДК рбхз $(0.4$ мг/л) (табл.). В воде оз. Комариное зафиксировано увеличение содержания $\mathrm{Cu}$, превышающего значение ПДК

\section{Выводы}

В результате проведения 10-летнего гидрохимического мониторинга оз. Комариное установлено, что с начала разработки апатит-нефелинового месторождения Олений ручей вода озера из нейтральной превратилась в щелочную, растет содержание основных ионов и изменилось их соотношение (главным образом анионов), увеличилась минерализация воды, значительно выросло содержание соединений биогенных элементов, в первую очередь азота, и некоторых микроэлементов ( $\mathrm{Sr}, \mathrm{Cu}, \mathrm{Mo}, \mathrm{F})$, в несколько раз превышающих величину ПДК

Работа выполнена в рамках тем НИР № 0226-2019-0045 и 0226-2019-0053 (сбор материалов) и поддержана из средств грантов РФФИ № 18-05-60125 (обработка материалов) и РНФ № 19-7710007 (интерпретация результатов).

\section{Литература}

1. Даувальтер В.А., Даувальтер М.В. Состояние подземных вод Мончегорского района // Вестник Кольского научного центра РАН. 2010. № 3. С. 26-33.

2. Даувальтер В.А., Даувальтер М.В. Геоэкологическая оценка состояния природных вод в зоне влияния комбината «Североникель». Мурманск. Изд-во: МГТУ. 2014. 216 с.

3. Даувальтер В.А., Даувальтер М.В. Экологическое состояние подземных вод Восточного рудника АО «Апатит» // Труды Ферсмановской научной сессии ГИ КНЦ РАН. 2019. № 16. С. 131-135. https://doi. org/10.31241/FNS.2019.16.027.

4. Даувальтер В.А., Кашулин Н.А. Влияние деятельности горно-металлургических пред-приятий на химический состав озера Имандра, Мурманская область // Биосфера. 2015. Т. 7. № 3. С. 295-314.

5. Даувальтер М.В., Даувальтер В.А. Гидрохимический режим озера Комариное, Хибинский щелочной массив, Мурманская область // Труды Ферсмановской научной сессии ГИ КНЦ РАН. 2020. № 17. C. 158-162. https://doi.org/10.31241/FNS.2020.17.029.

6. Добровольский В.В. Минералогия и ландшафтно-геохимическая характеристика чет-вертичных отложений Кольского полуострова // Материалы к геохимии ландшафтов Кольского полуострова. М. Изд-во: МГПИ. 1972. С. 3-51.

7. Кашулин Н.А., Денисов Д.Б., Сандимиров С.С., Даувальтер В.А., Кашулина Т.Г., Малиновский Д.Н., Вандыш О.И., Ильяшук Б.П., Кудрявцева Л.П. Антропогенные изменения водных систем Хибинского горного массива (Мурманская область). В 2 т. Апатиты. Изд-во: КНЦ РАН. 2008. Т. 1. 250 с. Т. 2. 282 с.

8. Кашулин Н.А., Сандимиров С.С., Даувальтер В.А., Кудрявцева Л.П., Терентьев П.М., Денисов Д.Б., Вандыш О.И., Валькова С.А. Аннотированные экологический каталог озер Мурманской области (Восточная часть. Бассейн Белого моря). В 2 ч. Апатиты. Изд-во: КНЦ РАН. 2012. Ч. 1. 221 с.

9. Красоткин И.С., Войтеховский Ю.Л, Лесков А.Л., Удобина В.С. Заброшенный молибденитовый рудник Тахтарвумчорр // Труды Ферсмановской научной сессии ГИ КНЦ РАН. 2005. № 2. С. 10-14.

10. Мироненко В.А., Мольский Е.В., Румынин В.Г. Изучение загрязнения подземных вод в горнодобывающих районах. Л. Изд-во: Недра. 1988. 279 с.

11. Мироненко В.А., Мольский Е.В., Румынин В.Г. Горнопромышленная гидрогеология. М. Изд-во: Недра. $1989.287 \mathrm{c}$.

12. Сулименко Л.П., Кошкина Л.Б., Мингалева Т.А., Светлов А.В., Некипелов Д.А., Макаров Д.В., Маслобоев В.А. Молибден в зоне гипергенеза Хибинского горного массива. Мурманск. Изд-во: МГТУ. 2017. 148 с.

13. Чукаева М.А., Матвеева В.А. Современное гидрохимическое состояние гидроэкосистем, находящихся под техническим влиянием АО «Апатит» // Водные ресурсы. 2018. Т. 45, № 6. С. 685-690. https://doi.org/10.1134/S0321059618060044.

14. Dauvalter V.A., Dauvalter M.V., Slukovskii Z.I. The dynamics of the chemical composition of surface water in the zone of influence of North-West Phosphorous Company JSC // IOP Conf. Series: Earth and Environmental Science. 2020. V. 539. 012026. https://doi.org/10.1088/1755-1315/539/1/012026. 